\title{
Apoptose na maturação placentária de vacas em diferentes estági- os de gestação: evidenciação imuno-histoquímica e bioquímica ${ }^{1}$
}

INDEX TERMS: Apoptosis, placenta, caspase 3, Bcl-2, bax, cattle.

RESUMO.- Apoptose tem um papel importante na manutenção da homeostase placentária, e o desequilíbrio desse processo pode comprometer a gestação. 0 objetivo do presente estudo foi avaliar a ocorrencia de apoptose em amostras de placenta de vacas em diferentes fases de gestação. Amostras de placentomos de 15 vacas saudáveis com $4(n=5), 6(n=5)$ e $9(n=5)$ meses de gestação foram colhidas e processadas rotineiramente para a histologia, imuno-histoquímica e isolamento de DNA. As lâminas obtidas foram coradas em HE, ou submetidas à análise imuno-histoquímica das proteínas pró-apoptóticas caspase-3 e Bax, e da proteína anti-apoptótica Bcl-2. O DNA

\footnotetext{
${ }^{1}$ Recebido em 30 de outubro de 2010.

Aceito para publicação em 8 de abril de 2011.

${ }^{2}$ Departamento de Patologia Geral, Instituto de Ciências Biológicas (ICB), Universidade Federal de Minas Gerais (UFMG), Av. Antonio Carlos 6627, Campus Pampulha, Belo Horizonte, MG 31270-010, Brasil. *Autor para correspondência: karinameca@yahoo.com.br
}

isolado foi submetido à eletroforese em gel de agarose para detecção da fragmentação internucleossômica do genoma. Os resultados de histomorfometria revelaram que as células apoptóticas aumentaram progressivamente com o avanço da gestação. Confirmou-se a apoptose pela fragmentação característica do DNA genômico, visualizada pelo clássico "padrão em escada" na eletroforese em gel de agarose. Adcionalmente, a imunoexpressão de caspase-3, Bax e Bcl-2 foram observadas em todas as amostras. Entretanto, a proteína caspase-3 apresentou marcação mais intensa em todos os tempos gestacionais, quando comparada com a marcação das proteínas Bcl-2 e Bax. Esses resultados confirmam e reforçam a importância da apoptose na maturação placentária. Além disto, indica que caspase-3, Bax e Bcl-2 estão envolvidas nos mecanismos de ativação da apoptose pela via intrínseca mitocondrial ao longo da gestação, contribuindo para o equilíbrio fisiológico da celularidade e renovação celular na placenta bovina. 
TERMOS DE INDEXAÇÃO: Apoptose, placenta, caspase 3, Bcl-2, bax, bovinos.

\section{INTRODUÇÃO}

Apoptose ou morte celular programada é um tipo de autodestruição celular dependente de energia e síntese protéica (Kerr \& Searle 1972). Está relacionada com a homeostasia na manutenção adequada do tamanho dos tecidos, exercendo um papel oposto ao da mitose (Gerschenson \& Rotello 1992, Kerr 1999). Desta forma, é um tipo de morte desejável, programada e seletiva, que envolve células isoladas sendo regulada intrínseca e extrinsecamente (Mcconkey et al. 1993). Tanto a proliferação celular quanto a apoptose desempenham papel importante na função placentária. Ambos os processos são inversamente proporcionais ao longo da gestação (Boos et al. 2003). A sua ocorrência aumenta consideravelmente no terço final da gestação participando efetivamente da maturação placentária (Smith et al. 1997, Boos et al. 2003).

Diferentes proteínas agem regulando a ativação ou inibição da apoptose como as moléculas da família Bcl-2, sendo que a Bcl-2 é anti apoptótica e a Bax é pró- apoptótica. Essas proteínas possuem a propriedade de oligomerizar formando poros na membrana celular da mitocôndria (Antonsson et al. 1997), permitindo a saida de citocromo $C$ para o citoplasma. Um dos principais eventos na apoptose é a ativação das caspases, as quais medeiam a maioria das mudanças morfológicas observadas no processo. As caspases são proteases do tipo cisteína que desempenham um papel fundamental nas clivagens proteolíticas do processo apoptótico (Chang \& Yang 2000, Grutter 2000). Atualmente são conhecidas pelo menos 12 tipos de caspases em mamíferos, classificadas em dois grupos principais: Caspases iniciadoras (Caspases -1, -2, -4, -5, -8, -9, -10, -11 e -12) e Caspases efetoras (Caspases - $3,-6$ e -7). Após a ativação das caspases efetoras o mecanismo de ativação da apoptose torna-se irreversível (Li \& Yuan 2008).

Várias alterações bioquímicas podem ser observadas quando a célula entra em apoptose e muitas delas têm sido utilizadas para detectar esse tipo de morte celular. Entre essas, ressalta-se a clivagem do DNA genômico em fragmentos múltiplos de 180-200 pares de bases, que é um quadro típico de processo de apoptose em vários sistemas celulares (Wyllie 1980, Cohen et al. 1992). Essa fragmentação característica do genoma é facilmente visualizada laboratorialmente pela eletroforese de DNA em gel de agarose, produzindo o clássico "padrão em escada" (Wyllie et al. 1980).

0 presente trabalho teve por objetivo evidenciar morfológica e bioquimicamente a apoptose em placenta de vacas em diferentes estágios de gestação através de eletroforese do DNA em gel de agarose e avaliar a imunoexpressão das proteínas Bcl-2, Bax e caspase 3, através de imuno-histoquímica visando a esclarecer o envolvimento das mesmas na via apoptótica ativada na maturação placentária.

\section{MATERIAL E MÉTODOS}

Foram utilizadas 15 placentas de vacas mestiças provenientes do Frigorífico Alvorada, situado no município de Igarapé, MG. Essas amostras foram divididas em três grupos (n=5): o Grupo I foi formado por placentomas obtidos de vacas com quatro meses de ges- tação; o Grupo II por placentomas de vacas com seis meses de gestação e o grupo III por placentomas de vacas com nove meses de gestação. A estimativa da idade fetal foi calculada pelo comprimento craniocaudal (CRL) do feto (Noakes 1990). As amostras dos placentomas foram processadas rotineiramente para histologia e para extração de DNA. Lâminas com secções de 5 Ìm foram coradas em HE para determinação do índice apoptótico e submetidas à reação de imuno-histoquímica das proteínas Bcl-2, Bax, caspase 3. A quantificação da apoptose foi feita em um número mínimo representativo de campos definido pela avaliação da evolução dos erros padrões de acordo com o aumento da amostragem (Moro et al. 2004). Brevemente, determinou-se o Índice Apoptótico (IA = somatório das células com morfologia de apoptose/somató cooperação rio das células totais x 100) em HE a partir da contagem de células no número máximo obtido de campos tomados aleatoriamente. Os campos foram contados em objetiva planacromática de 40x. Desses, formaram-se amostras crescentes de campos de 5 em 5 (5, 10,15 ...., etc) retirados aleatoriamente com reposição. Essas amostras foram caracterizadas por suas médias e respectivos erros padrões. Assim, o IA foi determinado em 10 campos/lâmina (calculados através da análise do erro padrão) tomados aleatoriamente para cada animal.

Na quantificação do IA foram consideradas todos os tipos de células da placenta em apoptose que apresentaram pelo menos três dos seguintes critérios morfológicos de inclusão (Vasconcelos \& Vasconcelos 1996): anoiquia (retração celular e perda de adesões entre células e membrana basal), condensação do citoplasma, condensação nuclear (compactação da cromatina nuclear em massas densas uniformes, alinhadas no lado interno da membrana nuclear, inclusive com aspecto de crescentes), fragmentação nuclear (convolução e fragmentação da membrana nuclear - sem cariorrexe ou ruptura), fragmentação celular (com formação dos corpos apoptóticos), fagocitose dos corpos apoptóticos pelas células adjacentes ("canibalismo celular") e ausência de inflamação.

A contagem das células foi feita manualmente em imagens digitalizadas obtidas dos campos histológicos em microscópio de luz com objetiva planapocromática de 40 vezes. Para a digitalização dessas imagens e contagem utilizou-se o analisador Kontron Elektronic GMBH com o programa KS300 versão 2.0.

Para a extração do DNA os tecidos placentários foram macerados na presença de $1 \mathrm{ml}$ de tampão de lise $(10 \mathrm{mM}$ Tris, $0,25 \%$ Triton $\mathrm{x}$ $100,1 \mathrm{mM}$ EDTA) $/ 0,125 \mathrm{~cm}^{3}$ de tecido, e agitados por $10-15$ segundos para ressuspender as células e completar a lise celular. Em seguida as amostras foram centrifugadas por 10 minutos a $10.000 \mathrm{~g} /$ $4^{\circ} \mathrm{C}$, e o sobrenadante foi descartado. Adicionou-se $800 \mu \mathrm{l}$ de Master Mix (790 $\mu \mathrm{l}$ de Tampão de digestão de proteína w/SDS e $10 \mu \mathrm{l}$ de Proteinase K $(20 \mathrm{mg} / \mathrm{ml})$ em cada amostra, que posteriormente foram incubadas overnight a $5^{\circ} \mathrm{C}$. Sequencialmente as amostras foram centrifugadas por 20 minutos a $10.000 \mathrm{rpm}$, e o sobrenadante transferido para um novo tubo onde foi acrescentado $200 \mathrm{ml}$ de Cloreto de Lítio 7,5 M, e as amostras colocadas em gelo seco por 10 minutos. Em seguida as amostras foram centrifugadas por 15 minutos a $13000 \mathrm{rpm}$ para precipitar proteínas e outras contaminações, e o sobrenadante transferido para um novo tubo. As amostras de DNA foram precipitadas em etanol 100\%, e lavadas uma vez em etanol 70\%, secadas à temperatura ambiente e ressuspensos em $\mathrm{H}_{2} \mathrm{O}$. Foi então realizada a eletroforese em gel de agarose a $1,5 \%$ em 1x TBE durante 55 minutos a 120v. Os géis foram corados com brometo de etídio e fotografados sob transiluminação UltraVioleta.

Para a técnica de imuno-histoquímica, secções desparafinadas da placenta foram submetidas à coloração pela estreptavidina-peroxidase. Foram utilizados anticorpos monoclonais anti-Bcl-2 clone 124 (DAKO M0887, Carpinteria, EUA), anti-Bax clone 2B2 (DAKO KAT80218, Carpinteria, EUA), e anti-caspase-3 clone JHM62, 


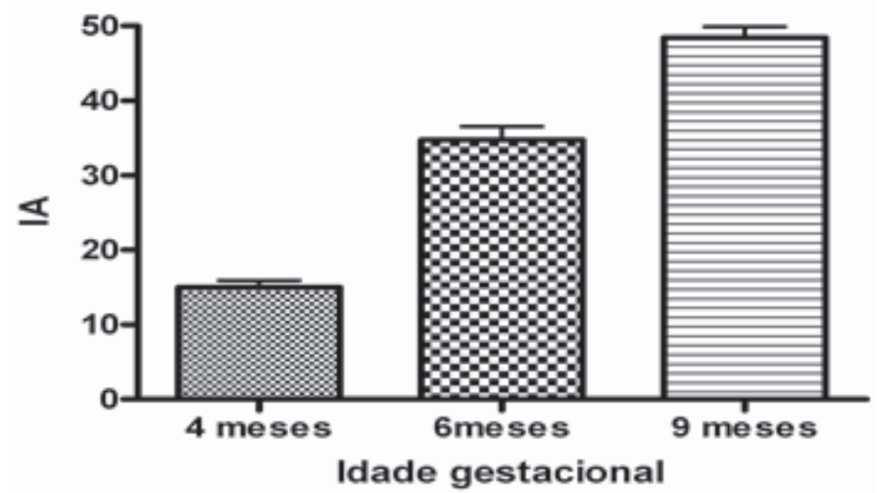

Fig.1. Análise dos índices apoptóticos nos grupos. Observar que houve aumento significativo do índice apoptótico com o avanço da idade gestacional.

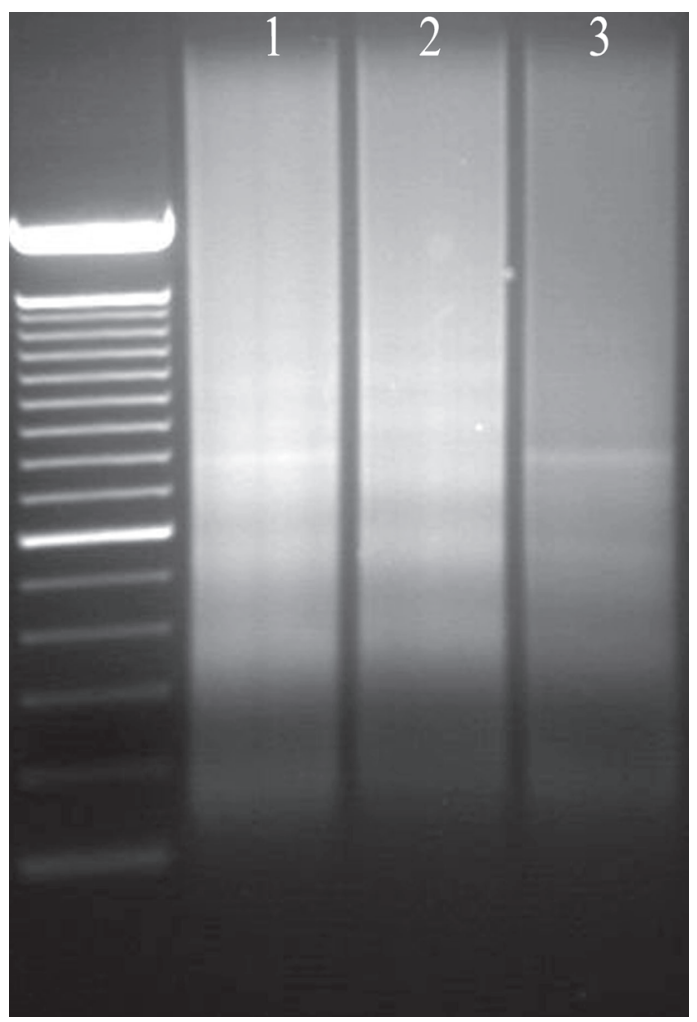

Fig.2. Eletroforese em gel de agarose de DNA genômico extraído de três amostras diferentes de placenta, (1) 4 meses de gestação, (2) 6 meses de gestação, (3) 9 meses de gestação. Observar intensa fragmentação internucleossômica do genoma, evidenciado pelo clássico "padrão em escada", indicativo de apoptose.
(Novocastra TM, CPP32), na diluição 1:50 (PBS 0,01M). As lâminas com $5 \mu \mathrm{m}$ foram inicialmente hidratadas em soluções de alcoóis decrescentes e, a seguir, foi realizada a recuperação antigênica com solução tampão EDTA (pH 8,0), durante 20 minutos à $95^{\circ} \mathrm{C}$ em banho-maria. 0 bloqueio da peroxidase endógena foi feito com o reagente Peroxidase Blocker, cobrindo as lâminas e incubando-as por 15 minutos à temperatura ambiente. Em seguida, os cortes foram lavados em água destilada e submetidas a banhos em tampão de lavagem (PBS 0,01, pH 7,0). Após secagem, os cortes foram incubados em câmara úmida por 30 minutos à temperatura ambiente e cobertos pelo anticorpo primário biotinilado. Logo após, as secções foram lavadas duas vezes com PBS e então incubadas com complexo estreptoavidina/HRP, em câmara úmida, durante 15 minutos, a temperatura ambiente. Após a lavagem em PBS, adicionou-se o cromógeno diaminobenzina (DAB) na diluição 1:50), que ficou incubado sobre as lâminas durante 5 minutos a temperatura ambiente. As lâminas foram contra-coradas com hematoxilina de Harris e montadas com bálsamo do Canadá.

\section{RESULTADOS}

A apoptose, reconhecida pelas características morfológicas estava presente em todas as idades gestacionais estudadas. 0 índice apoptótico do grupo com nove meses de gestação $(48,5 \pm 3,08)$ foi maior que o do grupo com seis meses $(34,78 \pm 3,97)$ que, por sua vez foi maior que o do grupo com quatro meses de gestação $(15,01 \pm 2,11)$ com $P<0,0001$. Demonstrando o aumento do índice apoptótico com o avanço da idade gestacional. A análise de variância mostrou que houve diferença estatisticamente significativa entre os grupos (Fig.1).

O gel da eletroforese do DNA genômico isolado das amostras de placenta de vacas nos diferentes estádios de gestação mostrou um "padrão de escada" compatível com a fragmentação internucleossômica do genoma característico da apoptose em todas as amostras estudadas (Fig.2).

A reação imuno-histoquímica para Bcl-2, Bax, caspase 3 foi positiva em todas as amostras, principalmente na junção materno-fetal, com variável intensidade da marcação. As células das vilosidades placentárias do Grupo I (4 meses), grupo II (seis meses) e Grupo III (9 meses) mostraram marcação positiva, citoplasmática e localmente extensa para Bcl-2 (Fig.3A-C). Várias células imunomarcadas apresentavam aspecto nuclear condensado e por vezes fragmentado (Fig.3C). As células das vilosidades placentárias de todos os grupos mostraram marcação positiva, citoplasmática e multifocal para Bax (Fig.4A-C). Várias células imunomarcadas apresentavam aspecto nuclear condensado e por vezes fragmentado

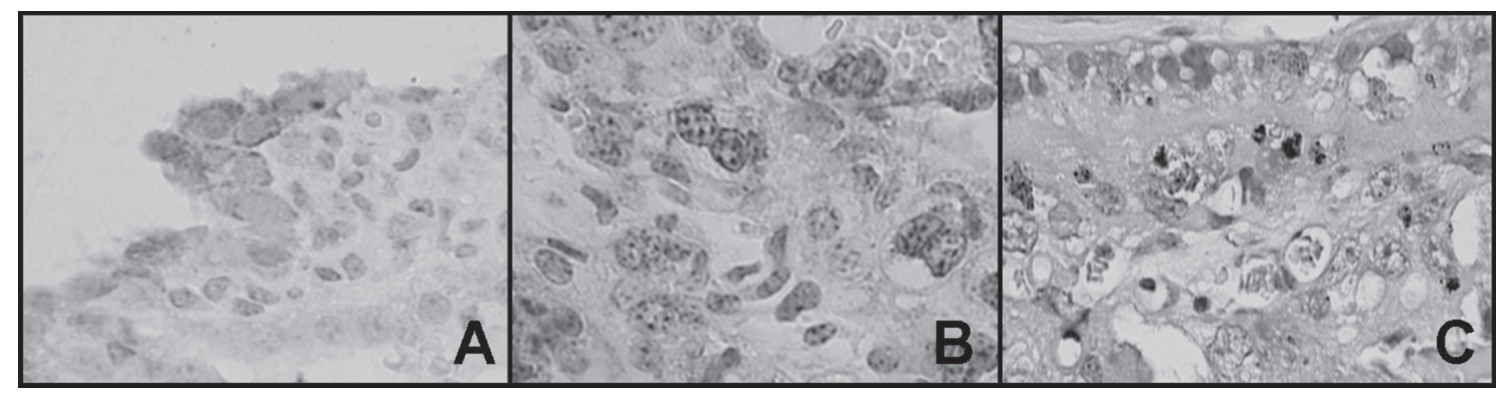

Fig.3. Placenta de vaca mostrando marcação imunoistoquímica da proteína Bax. Pequenos grumos castanho escuros nos núcleos define as células imunoreativas. (A) Placenta com quatro meses de gestação. (B) Placenta com seis meses de gestação. (C) Placenta com nove meses de gestação. Complexo streptavidina-peroxidase, 40x. 


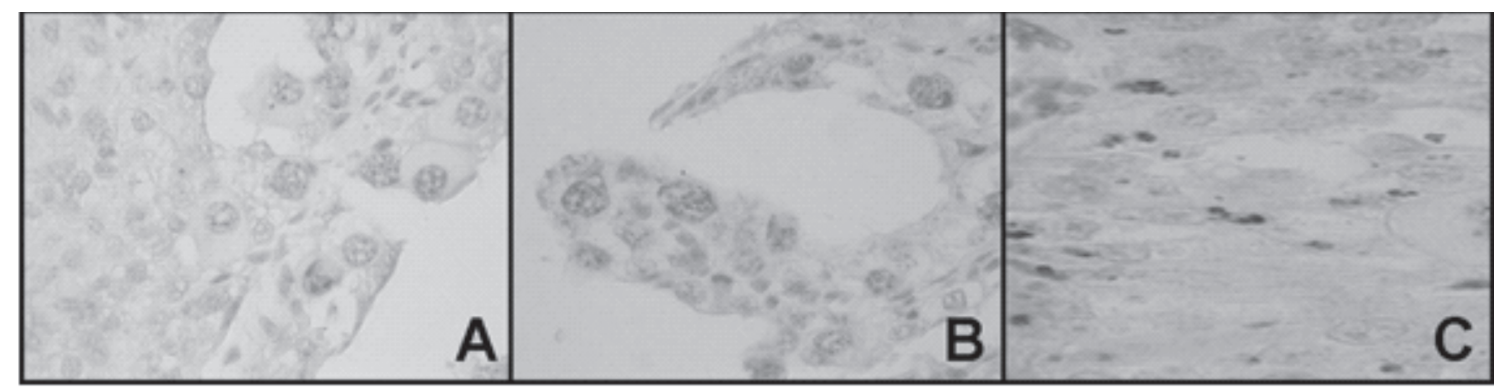

Fig.4. Placenta de vaca mostrando marcação imunoistoquímica da proteína caspase 3. Grumos acastanhados no citoplasma caracteriza as áreas imunoreativas. (A) Placenta com quatro meses de gestação. (B) Placenta com seis meses de gestação. (C) Placenta com nove meses de gestação. Complexo streptavidina-peroxidase, 40x.

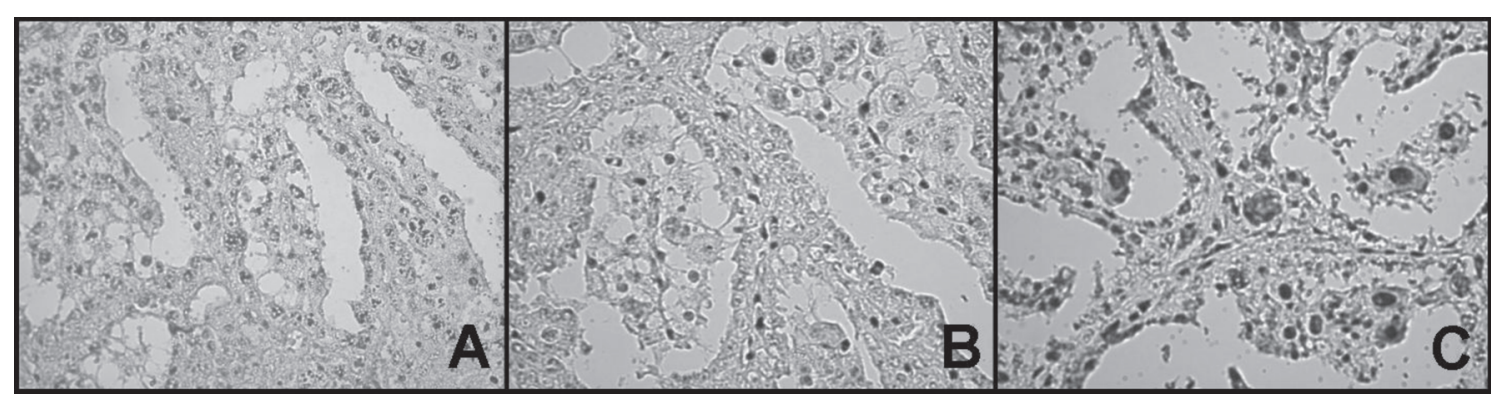

Fig.5. Placenta de vaca mostrando marcação imuno-histoquímica da proteína caspase 3. Grumos acastanhados no citoplasma caracteriza as áreas imunoreativas. (A) Placenta com quatro meses de gestação. (B) Placenta com seis meses de gestação. (C) Placenta com nove meses de gestação. Complexo streptavidina-peroxidase, 40x.

(Fig.4C). A reação imuno-histoquímica para caspase 3 mostrou uma marcação positiva intensamente e difusa em todos os grupos (Fig.5A-C).

\section{DISCUSSÃO}

A apoptose foi facilmente reconhecida morfologicamente em todos os campos microscópicos de todas as amostras processadas. Características peculiares do processo de apoptose tais como anoiquia, condensação da cromatina nuclear (formação de crescentes), retração citoplasmática e fragmentação nuclear e/ou citoplasmática (caracterizando a formação de corpos apoptóticos) foram observadas. A morte celular por apoptose desenvolveu-se na ausência de inflamação, que é característico da apoptose (Leist \& Nicotera 1998). Assim, observou-se o aumento do índice apoptótico com o avanço do estádio de gestação, semelhante aos resultados de estudos anteriores (Boos et al. 2003, Straszewski-Chavez et al. 2004). A apoptose ocorre na placenta em toda a gestação, mas com maior frequência no período final, em relação ao primeiro trimestre (Straszewski-Chavez et al. 2004). A apoptose é um evento fisiológico ativo que parece ser requerido tanto para a maturação, quanto para a liberação normal da placenta após o parto (Martins et al. 2004).

Variações de proliferação e das taxas de apoptose podem influenciar a maturação e liberação da placenta e comprometer a função, levando ao estresse fetal, anormalidades no desenvolvimento e ao aborto, como visto freqüentemente em gestações de bovinos provenientes de fertilização in vitro e os procedimentos de clonagem (Facciotti et al. 2009). Rici et al. (2009) relata que animais clonados tinha um menor número de células apoptóticas e uma maior capacidade proliferativa em oposição aos animais controle. Isso pode revelar a existência de uma relação entre essas mudanças nas proporções de uterino, trofoblasto e células epiteliais e da função placentária normal. Isso pode estar relacionado com placentação defeituosa no início da gravidez, insuficiência placentária durante a gravidez ou a falta de maturação da placenta e/ou fetal no final da gravidez, que podem contribuir para algumas das anormalidades após em manipulações de embriões in vitro, como a má preparação e início de parição, gestação prolongada e menor sobrevida pós-natal em alguns animais clonados.

Um padrão de degradação compatível com a fragmentação internucleossômica do genoma foi observado em todas as amostras confirmando a presença da apoptose. Uma das características bioquímicas da apoptose é a clivagem internucleossômica do genoma, que pode ser reconhecida pelo clássico "padrão em escada", por meio da eletroforese em gel de agarose, segundo Walker \& Gaastra (1983) e Platel (1994). Segundo Mesner Jr. \& Kaufmann (1997) e Sanders (1997) a eletroforese do DNA em gel de agarose é um método essencialmente qualitativo e o padrão em escada é produzido somente quando um considerável número de células de uma população sob estudo estiver no estágio tardio da apoptose. Se somente umas poucas células estiverem sofrendo clivagem do DNA, o padrão em escada do DNA é obscurecido, especialmente se a degradação do DNA ao acaso ocorrer juntamente com células morrendo por necrose.

A reação imuno-histoquímica para Bcl-2, Bax, caspases 3 foi positiva em todas as amostras, principalmente na junção materno-fetal, com intensidade da marcação foi variável. A reação imuno-histoquímica para caspases 3 mostrou uma marcação positiva intensamente e difusa. Evidenciando a participação das mesmas na apoptose que está ocorrendo nos 
três estágios gestacionais, o que confirma estudos anteriores feitos com essas mesmas amostras de placentônios, onde a PCR em tempo real demonstrou que o Bcl-2 e a caspase 3 foram expressos nos três estágios gestacionais estudados, sendo a expressão de Bcl-2 menor que a de caspase 8, que é menor que a de caspase 3 , apresentando o mesmo padrão, indicando que essas enzimas estão envolvidas na via apoptótica ativada na maturação placentária, exibindo um padrão de expressão ao longo da gestação (Meça et al. 2010).

\section{CONCLUSÕES}

Apoptose ou morte celular programada é um evento celular na placenta de vacas em diferentes estágios de gestação, como verificado morfologicamente e bioquimicamente em todas as amostras deste estudo.

A imuno-histoquímica mostrou a presença das proteínas Bcl-2, bax e caspase 3 nas três idades gestacionais estudadas, quatro, seis e nove meses.

Esses resultados confirmam e reforçam a importância da apoptose no processo de maturação placentária.

Além disto, indica que caspase-3, Bax e Bcl-2 estão envolvidas nos mecanismos de ativação da apoptose pela via intrínseca mitocondrial ao longo da gestação, contribuindo para o equilíbrio fisiológico da celularidade e renovação celular na placenta bovina.

Agradecimentos.- Esta pesquisa foi financiada pelo CNPq e pela FAPEMIG, a quem agradecemos pelo apoio financeiro.

\section{REFERÊNCIAS}

Antonsson B., Conti F., Ciavatta A.M., Montessuit S., Lewis S., Martinou I., Bernasconi L., Bernard A., Mermod J.J. \& Mazzei G. 1997. Inhibition of Bax channel-forming activity by Bcl-2. Science 277:370-372.

Boos A., Janssen V. \& Mülling C. 2003. Proliferation and apoptosis in bovine placentomes during pregnancy and around induced and spontaneous parturition as well as in cows retaining the fetal membranes. Reproduction 126:469-480.

Chang H.Y. \& Yang X. 2000. Proteases for cell suicide: functions and regulation of caspases. Microbiol. Mol. Biol. Rev. 64:821-846.

Cohen J.J. 1981. Programmed cell death in the immune system. Adv. Immun. 50:55-85.

Facciotti P.R., Rici R.E., Maria D.A., Bertolini M., Ambrósio C.E. \& Miglino M.A. 2009. Patterns of cell proliferation and apoptosis by topographic region in normal Bos taurus vs. Bos indicus crossbreeds bovine placentae during pregnancy. Reprod. Biol. Endocrinol. 7:25. doi:10.1186/14777827-7-25.

Gerschenson L.E. \& Rotello R.J. 1992. Apoptosis: A different type of cell death. Faseb J. 6:2450-2455.
Grutter M.G. 2000. Caspases: Key players in programmed cell death. Curr. Opin. Struct. Biol. 10:649-655.

Kerr J.F.R. 1999. Personal account of events leading to the definition of the apoptosis concept. Res. Problems Cell Differ. 23:1-10.

Kerr J.F.R. \& Searle J. 1972. A suggested explanation for the paradoxically slow growth rate of basal cell carcinomas that contain numerous mitotic figure. J. Pathol. 107:41-44.

Leist M. \& Nicotera P. 1998. Apoptosis, excitotoxicity, and neuropathology. Exp. Cell Res. 239:183-201.

Li J. \& Yuan J. 2008. Caspases in apoptosis and beyond. Oncogene 27:61946206.

Martins V.M.V., Marques Jr A.P., Vasconcelos A.C., Martins E., Santos R.L. \& Lima F.C.L. 2004. Placental maturation and expulsion in Holstein and Nelore cows. Arq. Bras. Med. Vet. Zootec. 56:157-167.

McConkey D.J., Orrenius S. \& Jondal M. 1993. Signal transduction in thymocyte apoptosis, p.19-30. In: Lavin M. \& Waters D. (Eds), Programmed Cell Death: The cellular and molecular biology of apoptosis. Harwood, Chur.

Meça K.K.O.L., Martins A.S., Del Puerto H.L. \& Vasconcelos A.C. 2010. Apoptose e expressão de Bcl-2 e das caspases 3 e 8 em placenta bovina, em diferentes estádios de gestação. Arq. Bras. Med. Vet. Zootec. 62:258-264.

Mesner Jr P.W. \& Kaufmann S.H. 1997. Methods utilized in the study of apoptosis. Adv. Pharmacol. 41:57-87.

Moro L., Vasconcelos A.C., Santos F.G.A., Alves C.M., Nunes J.E.S. \& Sampaio I.B.M. 2004. Determination of the minimal representative number of microscopic fields to quantify apoptosis in canine lymph nodes. Arq. Bras. Med. Vet. Zootec. 56:408-410.

Noakes D.E. 1990. Fertilidade e Obstetrícia em Bovinos. Varela, São Paulo. $25 \mathrm{p}$.

Plantel D.E. 1994. Gel electrophoresis: Essential data. John Wiley and Sons, Chichester, UK, p.136.

Rici R.E., Facciotti P.R., Ambrósio C.E., Maria D.A., Kfoury J.R. Jr, Bertolini M. \& Miglino M.A. 2009. Cell cycle and apoptosis in normal and cloned bovine near-term placentae. Anim. Reprod. Sci. 115:29-38.

Sanders E.J. 1997. Methods for detecting apoptotic cells in tissues. Histol. Histopathol. 12:1169-1177.

Smith S.C., Baker P.N. \& Symonds E.M. 1997. Placental apoptosis in normal human pregnancy. Am. J. Obstetr. Gynecol. 177:57-65.

Straszewski-Chavez S.L., Abrahams V.M., Funai E.F. \& Mor G. 2004. X-linked inhibitor of apoptosis (XIAP) confers human trophoblast cell resistance to Fas-mediated apoptosis. Mol. Hum. Reprod. 10:33-41.

Vasconcelos A.C. \& Vasconcelos M.M.A. 1996. Apoptose ou morte celular programada: um novo conceito em patologia? Revta Méd. Minas Gerais 5:103-108.

Walker J.M. \& Gaastra W. 1983. Techniques in Molecular Biology. MacMillan Publishing Company, New York. 333p.

Wyllie A.H. 1980. Glucocorticoid-induced thymocyte apoptosis is associated with endogenous endonuclease activation. Nature 284:555-556,

Wyllie A.H., Kerr J.F.R. \& Currie A.R. 1980. Cell death: The significance of apoptosis. Int. Rev. Cytol. 68:251-305. 